\title{
Application of DSSAT models for an agronomic adaptation strategy under climate change in Southern Italy: optimum sowing and transplanting time for winter durum wheat and tomato
}

\author{
Domenico Ventrella, Monia Charfeddine, Luisa Giglio, Mirko Castellini \\ Consiglio per la Ricerca e la sperimentazione in Agricoltura - Unità di ricerca per i Sistemi \\ Colturali degli Ambienti caldo-aridi (CRA-SCA), Bari, Italy
}

\begin{abstract}
Many climate change studies have been carried out in different parts of the world to assess climate change vulnerability and adaptation capacity of agricultural crops for certain environments characterized from climatic, pedological and agronomical point of view.

The objective of this study was to analyse the productive response of winter durum wheat and tomato to climate change and sowing/transplanting time in one of the most productive areas of Italy (i.e. Capitanata, Puglia), using CERES-Wheat and CROPGR0 cropping system models. Three climatic datasets were used: i) a single dataset (50 $\mathrm{km} \times 50 \mathrm{~km}$ ) provided by the JRC European centre for the period 19752005; two datasets from HadCM3 for the IPCC A2 GHG scenario for time slices with $+2^{\circ} \mathrm{C}$ (centred over 2030-2060) and $+5^{\circ} \mathrm{C}$ (centred over 2070-2099), respectively. All three datasets were used to generate synthetic climate series using a weather simulator (model LARS-WG). No negative yield effects of climate change were observed for winter durum wheat with delayed sowing (from 330 to 345 DOY) increasing the average dry matter grain yield under forecasted scenarios. Instead, the warmer temperatures were primarily shown to accelerate the phenology, resulting in decreased yield for tomato under the $+5^{\circ} \mathrm{C}$ future climate scenario. In general, under global temperature increase by
\end{abstract}

Correspondence: Domenico Ventrella, Consiglio per la Ricerca e la Sperimentazione in Agricoltura, Unità di ricerca per i Sistemi Colturali degli Ambienti caldo-aridi (CRA-SCA), via Celso Ulpiani 5, 70125 Bari, Italy.

E-mail: domenico.ventrella@entecra.it

Key words: DSSAT model, climate change, winter durum wheat, tomato, sowing time, transplanting time.

Acknowledgements: this research was funded by CLIMESCO Evolution of cropping systems as affected by climate change project, contract n. 285, 20/02/2006 (Ministry for Education, University and Research).

Received for publication: 8 April 2011.

Accepted for publication: 16 December 2011.

CC Copyright D. Ventrella et al., 2012

Licensee PAGEPress, Italy

Italian Journal of Agronomy 2012; 7:e16

doi:10.4081/ija.2012.e16

This article is distributed under the terms of the Creative Commons Attribution Noncommercial License (by-nc 3.0) which permits any noncommercial use, distribution, and reproduction in any medium, provided the original author(s) and source are credited. $5^{\circ} \mathrm{C}$, early transplanting times could minimize the negative impact of climate change on crop productivity but the intensity of this effect was not sufficient to restore the current production levels of tomato cultivated in southern Italy.

\section{Introduction}

Climate change and climate variability are real concerns for the sustainable development of agriculture worldwide. While agriculture is a complex sector with the agricultural still being dependent on climate, because seasonal patterns of light, temperature, water, air humidity and carbon dioxide concentration $\left(\mathrm{CO}_{2}\right)$ are the main determinants for crop growth and consequently for crop productivity.

All the climate change scenarios predicted for the Mediterranean regions at the end of the $21^{\text {st }}$ century forecast increase in solar radiation, $\mathrm{CO}_{2}$, temperatures and frequency of extreme events (storm, floods, heat wave and dry spelling) while the precipitation, at seasonal scale, is not always projected to decrease. In any case, the anthropic activities that depend on high water abstraction and use, such as irrigated agriculture, could be negatively affected by the future water scarcity combined with the increment of atmospheric evaporative demand (EEA, 2007). In particular, many studies on climate change highlighted a large variability of the Mediterranean area (Gibelin and Déqué, 2003; IPCC, 2007; Giorgi and Lionello, 2008).

Agricultural crop production is certainly going to be affected under future climate change. Even so, because of regional differences in both natural and anthropogenic factors that control plant responses, the intensity of climate impacts on crop yields can vary depending upon location, climate change scenarios and crop (Tubiello et al., 2002).

A large number of studies have analyzed the potential effects of climate change on different crops productivity response (Rosenzweig and Tubiello, 1996; Lal et al., 1998; Tubiello and Ewert, 2002; Parry et al., 2004; Trnka et al., 2004; Ventrella et al., 2009a). In particular, temperature rising can have either negative and positive effects on crop yield, but generally it have been found to reduce yields and quality of many crops. So, for instance, Stuczyinski et al. (2000) reported that drier conditions and rising temperatures in the Mediterranean region and parts of eastern Europe may lead to lower yields. In fact, crop response to temperature increment depends on the degree of temperature increase as well as the development stage of the plant. Hatfield (2008) demonstrated that any increase in temperature result in reduced grain filling period for wheat and other some grain species and consequently, lower crop yields. In the case of tomato, depending on production area, the yield is projected to decrease about $12.6 \%$ for $1.2^{\circ} \mathrm{C}$ rise above $25^{\circ} \mathrm{C}$, assuming a non-linear yield response (Hatfield, 2008). In Argentine soybean yield was projected to increase, maize yield decrease, but yield projections for wheat were mixed depending 
upon projected temperature increases (Magrin et al., 1997). Similar yield results were found in maize and wheat in the southern part of Romania (Cuculeanu et al., 1999).

In southern Italy, Giglio et al. (2010) reported, in a temporal-spatial study using Decision Support System for Agrotechnology Transfer (DSSAT), that durum wheat yields were predicted to increase under different GCMs climate change scenarios. However, Tubiello et al. (2000) found that projected wheat yields using CropSyst would decrease under two climate change scenarios in two Italian locations (in the northern and southern part). Nevertheless, to overcome the negative impact of climate change and variability on crop yield, especially in vulnerable regions where agriculture is most sensitive to climatic fluctuation, many adaptations strategies were suggested. Ventrella et al. (2011) used the cropping system models CERES-Wheat and CROPGRO-Tomato of DSSAT to analyse the response of winter durum wheat and tomato crops to climate change, irrigation and nitrogen fertilizer managements.

Advance or delay in sowing date, increasing nitrogen fertilizer application, optimization of irrigation management, reduced plant population density, improvement in soil moisture by conservative tillage system and choice of crop or cultivar with the best thermal requirement represent the main agronomic adaptation techniques able to maintain current levels of crop production in future and consequently to limit potential damages of climate change.

Importantly, Stigter et al. (2005) suggested that response farming should not only be considered with respect to fitting the cropping seasons to variable rainfall patterns but also for fitting it to variable temperature patterns. In particular, they cite the case study reported by Van Viet (2001) where either planting date or a combination of planting date and variety could be varied, to make sure that rice was flowering in decades for which the required optimal temperatures had been forecasted. Mizina et al. (1999) reported that adaptation is certainly an important component of any policy response to climate change in agricultural sector. Besides, several studies show that without adaptation, climate change may create considerable problems related to agricultural production and agricultural economy in many areas. However, with adaptation, vulnerability can be reduced and there are numerous opportunities to be realized (Rosenzweig and Parry 1994; Wheaton and Mclver 1999; Smit and Skinner, 2002; Wall and Smit, 2005). According to Salinger et al. (2005), the range of adaptation options for managed systems such as agriculture and forestry is generally increasing because of technological advances, thus opening the way for reducing the vulnerability of these systems to climate variability. Climate change impact studies in agriculture are now carrying out utilizing crop models in order to simulate crop production and economic balances, under any climate conditions, soil and management practices (Hoogenboom, 2000 ), combining also the effects of $\mathrm{CO}_{2}$ fertilization with plant physiological processes (Salinger et al., 2005).

Over the past decades, a diversity of crop simulation models has been developed and extensively used to predict development, growth and yield of crops. However, such simulation models vary second the objectives, production conditions (potential, under limited water and nutrient availability) and level of wished details. DSSAT (Jones et al., 2003), EPIC (Erosion-Productivity Impact Calculator; Williams et al., 1989); CropSyst (Stöckle et al., 2003) are some examples of crop environmental-growth simulation models successfully evaluated.

In particular, DSSAT is as a comprehensive decision support system that consists of a suite of crop simulation models, not only predict the effects of climate change on crop production but can also evaluate the best management and genetic options under climate change scenarios. The ability of DSSAT to evaluate management and genetic options is a powerful tool for studying the impacts of climate change and assessing useful adaptation strategies to reduce the potentially negative effects of climate variability such as sowing date, row spacing, plant density, irrigation and fertilization. It has been successfully employed over the last 15 years worldwide in many range of applications, including climate change, precision agriculture and crop management such as $\mathrm{N}$ fertilization, irrigation and planting or sowing date (Arora et al., 2007; Cabrera et al. 2007; Rinaldi et al., 2007; Rinaldi and Ubaldo, 2007; Brassard and Singh, 2008; Thorp et al., 2008; Timsina et al., 2008; Luo et al., 2009; Ventrella et al., 2009b; Iqbal et al., 2011).

Based on these considerations, the overall objective of this study was to evaluate the optimization of the sowing or transplanting times, as adaptation strategies to forecasted climate change for the cultivation of winter durum wheat and tomato in southern Italy, utilizing the Cropping System Model (CSM)- CERES-Wheat and CROPGRO chosen for their ability to simulate crop growth, phenology and yield.

\section{Materials and methods}

\section{Study area}

This study was focused on the Capitanata area (Lat. 41.76-42.45 N, Long. 14.97-15.62 E, $90 \mathrm{~m}$ asl) of approximately $4000 \mathrm{~km}^{2}$ and located in the northern part of the Apulia Region in southern Italy. The Capitanata is considered one of the most important areas in Italy for the production of winter durum wheat and tomato and, secondarily, for other crops such as cabbage, olive and grapes. Typically, the soils are deep, clay or silty-clay, and vertisol of alluvial origin. The climate is classified as accentuated thermomediterranean (Unesco-FAO classification), with temperatures that may fall below $0^{\circ} \mathrm{C}$ in winter and exceed $40^{\circ} \mathrm{C}$ in summer. Rainfall is unevenly distributed throughout the year, and is mostly concentrated in the winter months with a longterm annual average of $550 \mathrm{~mm}$.

\section{Climatic data}

For the 1975-2005 time period, observed daily data $\left(\mathrm{T}_{\min }, \mathrm{T}_{\max }\right.$, rainfall and global solar radiation) were extracted for the closest grid $(50 \times 50 \mathrm{~km})$ from the MARS JRC archive (MARS project http://mars.jrc.ec.europa.eu).

For the future, time slices were centred over the 2030-2059 $\left(+2^{\circ} \mathrm{C}\right)$ and $2070-2099\left(+5^{\circ} \mathrm{C}\right)$ time periods, respectively. The daily data $\left(\mathrm{T}_{\min }\right.$, $\mathrm{T}_{\max }$, rainfall and global solar radiation) were obtained from HadCM3 experiment for the A2 SRES IPCC scenarios. Because of the coarse original Global Climate Models (GCMs) resolution, a statistical downscaling procedure, based on the LARS Weather Generator (Semenov and Barrow, 1997; Semenov, 2007) was adopted in order to reproduce at regional scales the future climate at the time of average global warming of $2^{\circ} \mathrm{C}$ and $5^{\circ} \mathrm{C}$ over a nearest grid cell to the Capitanata area. The results of HadCM3 under the A2 IPCC scenario were used to derive the forcing factors for the downscaling procedure.

For the present time, observed daily data, extracted from MARS JRC archive, were used for the local calibration of the LARS weather generator and for producing synthetic daily weather data representing the Baseline scenario. For the two future time slices, daily data HadCM3 were used to calculate the perturbing variables of LARS-WG (monthly precipitation, temperature and solar radiation changes, as well as changes in both the length of the wet and dry series and changes in the standard deviation of temperature), and were also used for producing synthetic daily weather data representing $+2^{\circ} \mathrm{C}$ (Anomaly_2) and $+5^{\circ} \mathrm{C}$ (Anomaly_5) future scenarios.

Different concentrations of $\mathrm{CO}_{2}$, in order to undertaken their impacts, were considered: 360,550 and $700 \mathrm{ppm}$ for Baseline, Anomaly_2 and Anomaly_5, respectively. 


\section{Crop simulation models}

The CERES-Wheat (Crop Environment REsources Synthesis) and CROPGRO models, both included in the Decision Support System for Agrotechnology Transfer (DSSAT) software package (Jones et al., 2003), were used in order to carry out the simulation of winter durum wheat (Triticum turgidum L., subs. durum [Desf.]) and tomato (Lycopersicon aesculentum L.), respectively. The two cropping system models were previously calibrated and validated at the test area and for the winter durum wheat - cv. Simeto (Rinaldi, 2001) and tomato - variety PS 1296 (Rinaldi et al., 2007).

CERES and CROPGRO models were developed to predict the growth of cereals (Ritchie et al., 1998) and of a wide range of grain legumes (Hoogenboom et al., 1994; Boote et al., 1998) as well as non legumes such as tomato (Scholberg et al., 1997), respectively. They are considered the two primary crop models in the DSSAT software and a detailed description can be found in Jones et al. (2003), Rinaldi et al. (2007), Tsuji et al. (1998), Tubiello et al. (1995). Basically, they are dynamic simulation models that simulate the impacts of weather, soil properties, genotype and management on crop daily phenological development and growth, dynamics of soil water and nitrogen. Both models calculate potential biomass accumulation as the product of radiation use efficiency and intercepted photosynthetically active radiation (PAR). The percentage of incoming PAR intercepted by the canopy is an exponential function of leaf area index (LAI). A minimum inputs including daily weather data (mainly $\mathrm{T}_{\max }$ and $\mathrm{T}_{\min }$, solar radiation, and precipita-

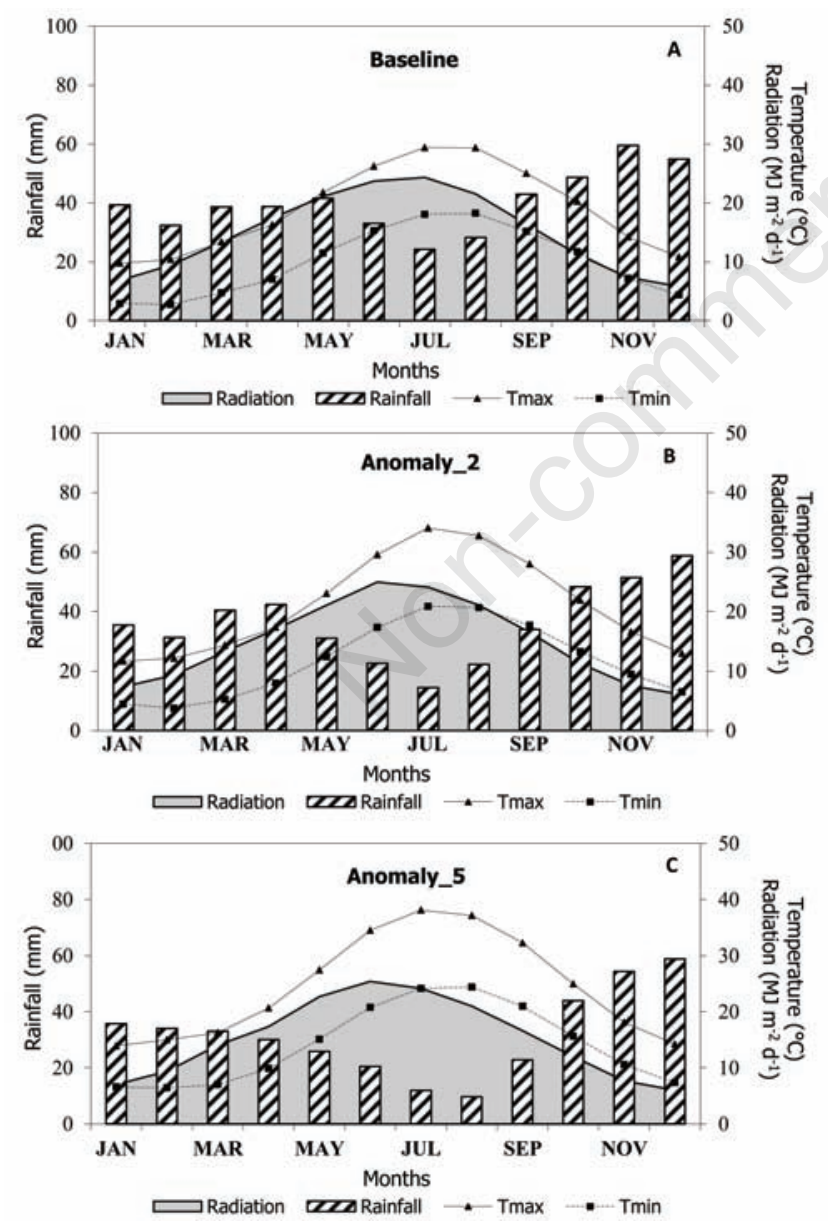

Figure 1. Monthly average of air temperature (maximum and minimum), solar radiation and rainfall of the three scenarios: Baseline (A), Anomaly_2 (B) and Anomaly_5 (C). tion), soil properties, crop characteristics and management information, are required to run CERES and CROPGRO.

\section{The sowing-transplantig time as adaptation strategies}

The seasonal analysis option of DSSATs model was used to predict the response of winter durum wheat and tomato under the three climate scenarios. Thus, for both crops, cycle duration, dry matter yields and some water balance parameters were estimated and discussed.

The agronomic adaptation option evaluated in this study was the sowing and transplanting time in order to evaluate the response curves of crop yield and, consequently, to individuate the optimal range for sowing and transplanting under different climate scenarios. In particular, the optimal current sowing or transplanting dates was considered November $28^{\text {th }}$ (330 day of year, DOY) and April $30^{\text {th }}(120$ DOY) for winter durum wheat and tomato, respectively. In order to better identify the response curve of the two crops to sowing/transplanting time, other four sowing dates were also considered for each crop. In particular, for winter durum wheat we considered 2 spaced sowings of 15 days, while in the case of tomato we considered a 10-day interval. In addition, in both crops simulations, identical initial soil conditions were considered while the harvest date was simulated by the model at crop maturity. The potential evapotranspiration was calculated through the PriestleyTaylor equation.

For the rainfed winter durum wheat, $120 \mathrm{~kg}$ of $\mathrm{N} \mathrm{ha}^{-1}$ was applied in two times (before sowing with ammonium phosphate and as a top dressing with ammonium nitrate). For tomato an automatic irrigation (as drip method) was adopted starting when $45 \%$ of the crop available water (CAW) in the upper $0.3 \mathrm{~m}$ of the soil depth was depleted. $\mathrm{N}$ fertilization was scheduled in two equal applications, before transplanting with ammonium phosphate and as a top dressing with ammonium nitrate with and $150 \mathrm{~kg}$ of $\mathrm{N} \mathrm{ha}^{-1}$.

\section{Results and discussion}

\section{Climatic scenarios}

Figure 1 reports the mean monthly maximum $\left(\mathrm{T}_{\max }\right)$ and minimum $\left(\mathrm{T}_{\min }\right)$ temperatures, solar radiation and rainfall of Baseline (19752005) and future climate scenarios (Anomaly_2 and Anomaly_5). Compared to the Baseline scenario, mean annual $\mathrm{T}_{\max }$ was predicted to increase by 2.3 and $5.5^{\circ} \mathrm{C}$ in Anomaly_2 and Anomaly_5, respectively. Similar trend was observed for mean annual $\mathrm{T}_{\min }$, with rising values about 1.7 and $4.2^{\circ} \mathrm{C}$ under Anomaly_2 and Anomaly_5, respectively.

However, the mean annual rainfall was projected to decrease by 10.4 and $20.9 \%$ for Anomaly_2 and Anomaly_5 scenarios, respectively.

\section{Winter durum wheat}

The response curve of sowing-flowering period under the three climate scenarios is shown in Figure 2. The curves had the same curvilinear trend with a lack of response (plateaux) between 300 and 315 DOY and a steep linear reduction up to 360 DOY. Compared to the Baseline scenario, under Anomaly_2 a shortening of the vegetative period between 18 and 9 days was observed from 300 to 360 DOY. Under Anomaly_5 a stronger reduction of the period was detected with 37 and 27 days. The curves of Sowing-Maturity duration, reported in the part B of the Figure 2, highlighted a linear trend that characterized the climate scenarios with smaller variations than the vegetative period. In other words, the reduction was higher in the vegetative cycle (i.e. sowing-anthesis phase), whereas in the reproductive cycle (i.e. anthesismaturity phase) a small extension of few days was observed.

Figure 3 summarizes the relationship between yield and sowing date for winter durum wheat in Baseline and future scenarios. Unlike the 
relationships described above, in this case an evident modification of the response curve characterized the three scenarios. In the Baseline the effect of sowing time on durum wheat yield was quite negligible. Instead, under future scenario the response curves became significant and were characterized by a first segment with a linear trend from 300 to 330 DOY followed by a plateaux up to $360 \mathrm{DOY}$. Such plateaux were placed around values of 4.7 and $4.0 \mathrm{t} \mathrm{ha}^{-1}$ under Anomaly_2 and Anomaly_5, respectively.

Compared to the date of 300 DOY, delaying the sowing at 345 DOY winter durum wheat increased gain yield by $29 \%$ under Anomaly_2 and by $41 \%$ under Anomaly_5. Another important consideration is that under Anomaly_5 it was possible to restore the same productivity level of Baseline period, obtained at reference sowing time ( $3.9 \mathrm{t} \mathrm{ha}^{-1}$ at 330 DOY), when the winter durum wheat was sowed after such date. Therefore, crops sown later had the best chance of optimal temperature during flowering and low water stress during grain filling, contributing to greater yields. Overall, air temperature rise during the crop cycle was 1.8 and $4.3^{\circ} \mathrm{C}$ for Anomaly_2 and Anomaly_5 respectively. Such an increase in temperature did not have a significant negative effect on winter durum wheat productivity under elevated $\mathrm{CO}_{2}$ concentration especially at later sowing and despite the reduction of vegetative period. As the other $\mathrm{C} 3$ crops this finding was not surprising for durum wheat because of positive affected by $\mathrm{CO}_{2}$ fertilisation in terms of photosynthesis that counterbalanced the expected stomatal closure. Instead, Alexandrov and Hoogenboom (2000) reported that all transient GCM climate change scenarios of the $21^{\text {st }}$ century projected a reduction in winter wheat yields in Bulgaria because a likely larger reduction of rainfall than our simulations.

The grain harvest index (HI, as grain dry weight/total above-ground dry weight at harvest) improved with delay sowing times with a higher increments under future scenarios than Baseline (Figure 4). In northern European regions, Olesen et al. (2007) reported similar results and they attributed this result to positive effect of raising $\mathrm{CO}_{2}$ atmospheric concentration.

The curves of seasonal crop evapotranspiration (ETc) were almost linear without particular differences between scenarios but with reductions of about 15 and 20\% under Anomaly_2 and Anomaly_5, respectively, when compared to Baseline and regardless of sowing date (Figure 5).

The decrease of ETc at seasonal scale under future scenarios can be attributed to the reduction of crop cycle and such lower evapotranspiration was only partially compensated by the expected increase of evaporative demand of the atmosphere due to temperature increase. The trends of water use efficiency (WUE, gain yield/ETc) were very similar to those reported for dry matter grain yield (Figure 6).

\section{Tomato}

In Figure 7 vegetative and reproductive cycle of tomato for different transplanting times are reported. For tomato the relationship vegetative duration-transplanting time was a decreasing polynomial curve of second degree with reduction of 26, 25 and 18 days under Baseline, Anomaly_2 and Anomaly_5 respectively, from 100 to 140 DOY. The increasing temperatures of climate change caused a mean shortening of vegetative period of 5 and 14 days in Anomaly_2 and Anomaly_5, respectively.

The trends reported in the part B of Figure 7 were very similar to those of vegetative period while the reductions, following delayed transplanting, were 28,28 and 21 days corresponding to reductions of reproductive periods of 3,3 and 2 days under Baseline, Anomaly_2 and Anomaly_5 respectively. In other words, as in the case of winter durum wheat, also for tomato the increasing temperature induced a reduction in the vegetative cycle of tomato. Finally, considering the transplantingmaturity duration and compared to Baseline scenario, the reduction of phenological cycle was 12 and 31\% under Anomaly_2 and Anomaly_5,

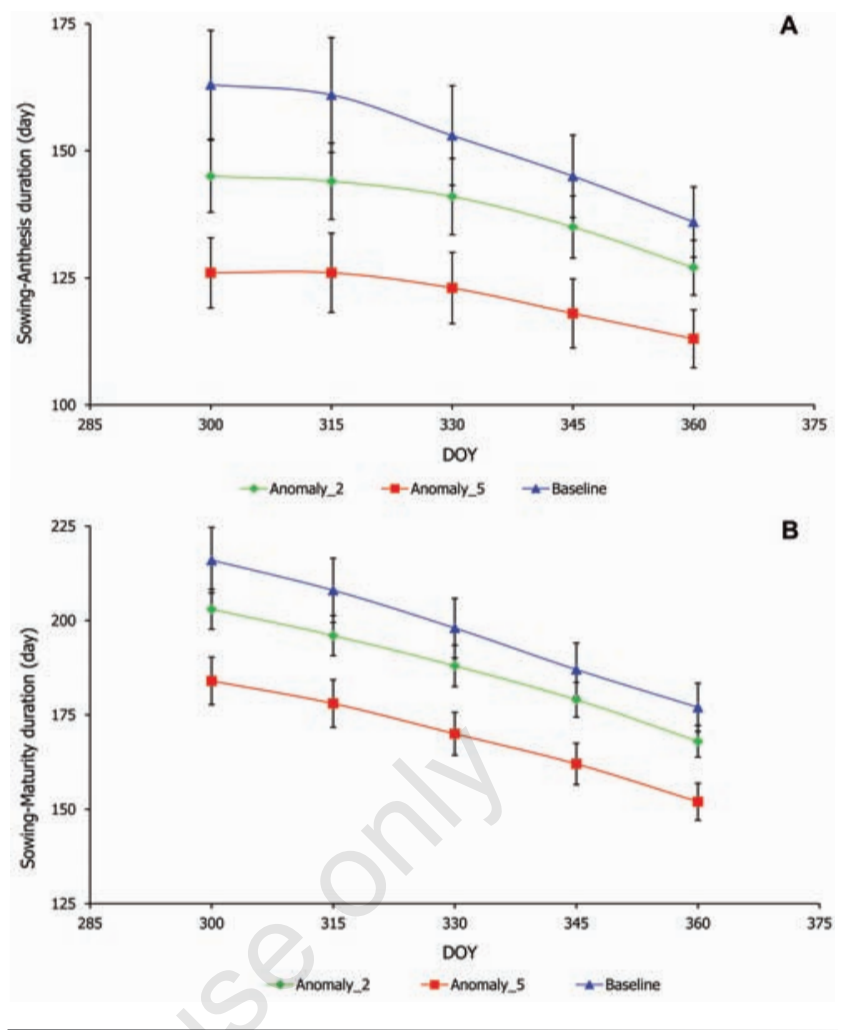

Figure 2. Effects of sowing date on simulated vegetative (A) and reproductive $(B)$ duration of durum wheat under climate change scenarios.

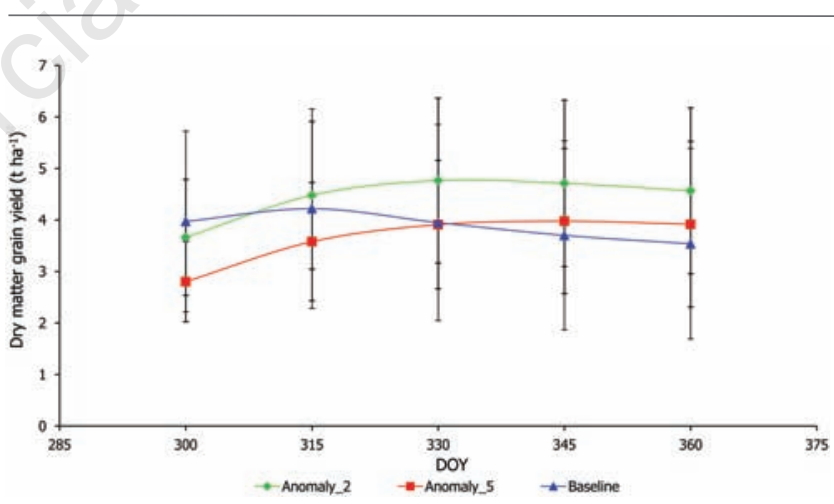

Figure 3. Effects of sowing date on simulated dry matter grain yield of durum wheat under climate change scenarios.

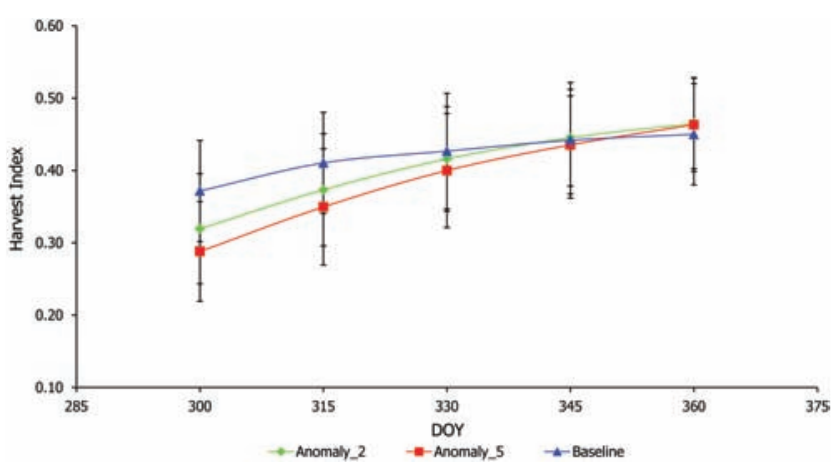

Figure 4. Effects of sowing date on simulated harvest index of durum wheat under climate change scenarios. 
respectively.

Simulation results of tomato dry matter fruit yield, as affected by different sowing dates, are shown in Figure 8. Not surprisingly, the lowest yield levels were predicted in Anomaly_5 scenarios with mean reductions of about 20\% respect to the Baseline. Under Anomaly_2, the yield decrease, was about 10\% compared to Baseline period. In Baseline and Anomaly_2 scenarios no response of tomato yield to transplanting time was predicted. Instead, under Anomaly_5 the sensitivity of tomato to transplanting time increased. The first two times (100 and 110 DOY) were characterized by a mean yield of $7 \mathrm{t} \mathrm{ha}^{-1}$. Delaying the tomato transplanting, respect to the level of $7 \mathrm{tha}^{-1}$, the yield decreased of 5 , 9 and 13\% for 120, 130 and 140 DOY respectively. In other words, under Anomaly_5 early transplanting times have partially counterbalanced the negative effects of the high temperatures of Anomaly_5 but such effect was not enough to re-establish the productive level of Baseline scenario $\left(8.5 \mathrm{t} \mathrm{ha}^{-1}\right)$. In addition, the temperature rise of future scenarios induced unfavorable conditions for flowering and fruit formation stages and on the other hand, much favorable for vegetative growth as demonstrated by un increase in LAI maximum values by $35 \%$ and $58 \%$ under Anomaly_2 and Anomaly_5, respectively, compared to Baseline (data not shown). This is the reason explaining the lower harvest index predicted in future scenarios (Figure 9). Under Baseline, HI increased exponentially with delaying transplanting times from 0.55 to 0.64 while it didn't change under future scenarios around an average

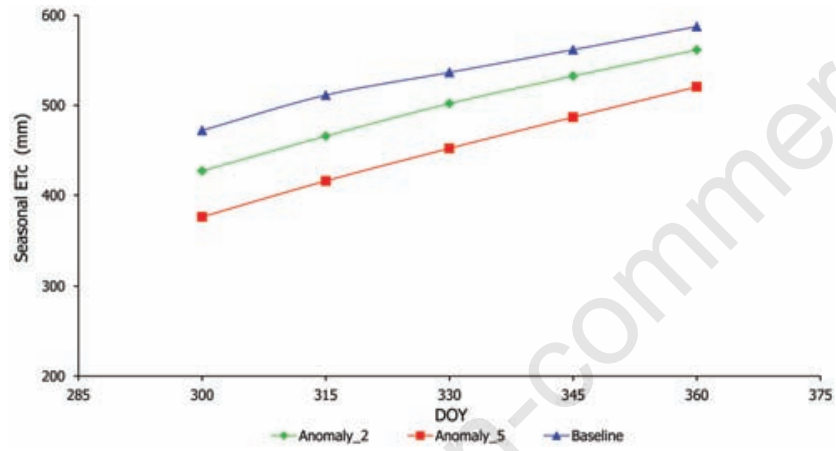

Figure 5. Effects of sowing date on simulated seasonal potential evapotranspiration of durum wheat under climate change scenarios.

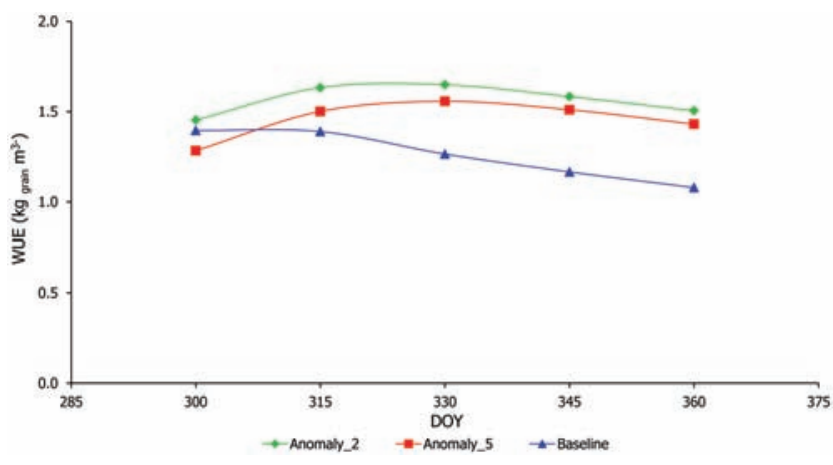

Figure 6. Effects of sowing date on simulated water use efficiency in grain yield of durum wheat under climate change scenarios.
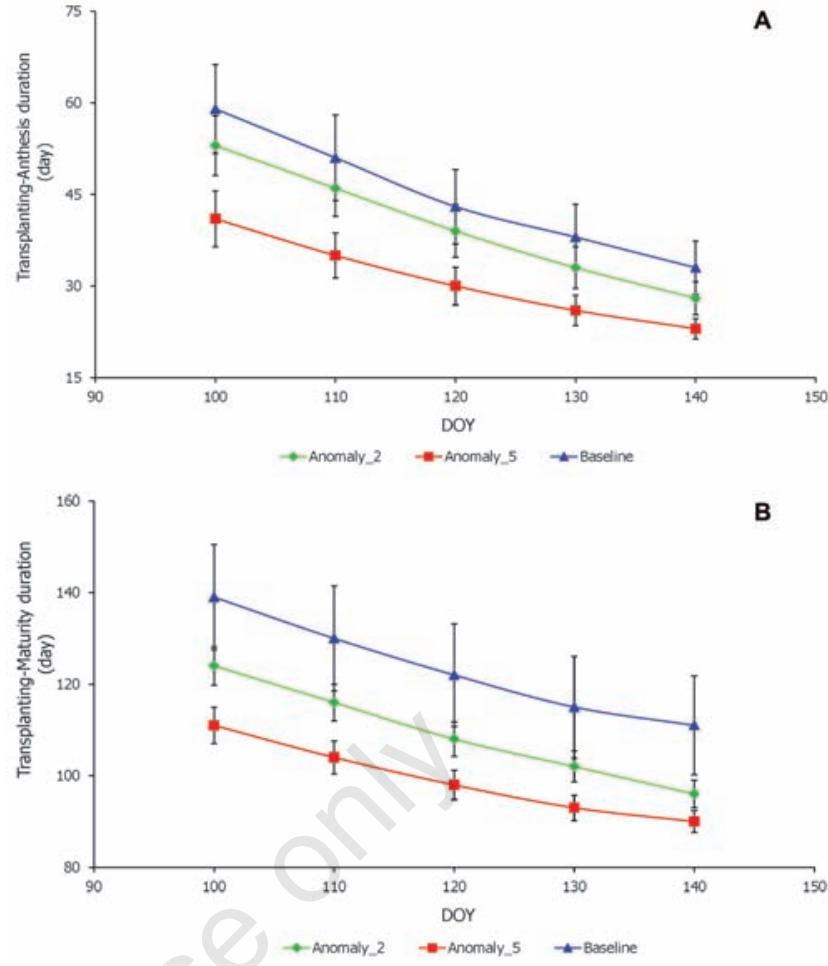

Figure 7. Effects of transplanting date on simulated vegetative (A) and reproductive $(B)$ duration of tomato under climate change scenarios.

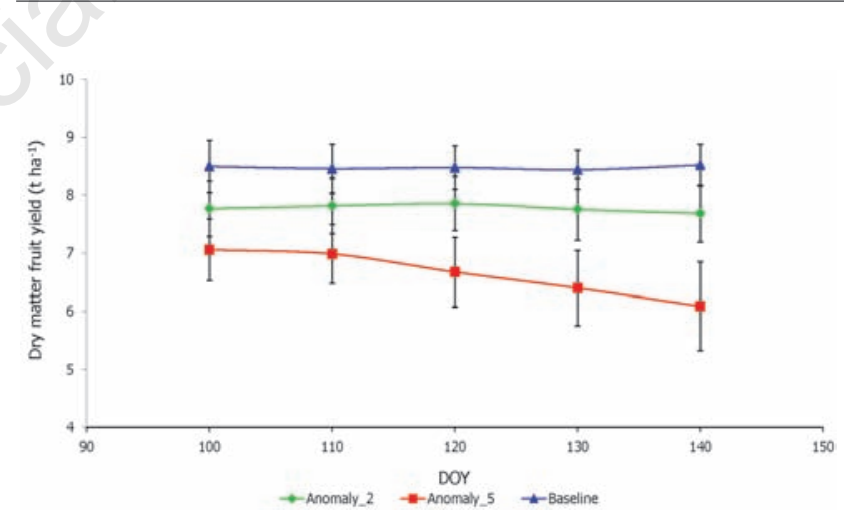

Figure 8. Effects of sowing date on simulated dry matter fruit yield of tomato under climate change scenarios.

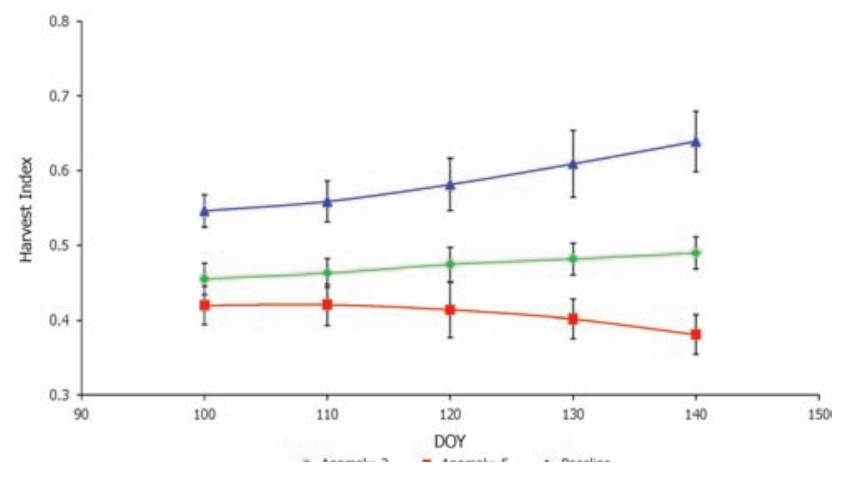

Figure 9. Effects of sowing date on simulated harvest index of tomato under climate change scenarios. 
plasticity of the plants to high temperatures and $\mathrm{CO}_{2}$ concentrations.

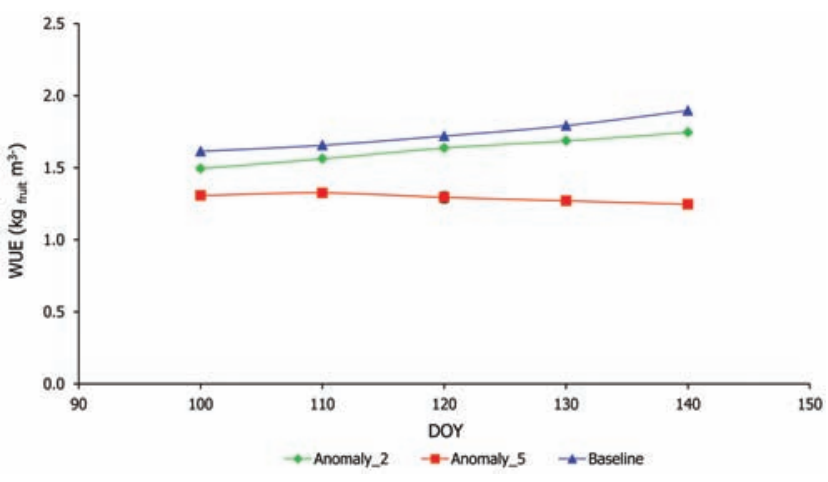

Figure 10. Effects of sowing date on simulated water use efficiency in fruit yield of tomato under climate change scenarios.

of 0.47 and 0.41 in Anomaly_2 and Anomaly_5, respectively (Figure 9).

Figure 10 shows tomato WUE curves. The lowest values were predicted under Anomaly_5 $\left(1.4 \mathrm{~kg} \mathrm{~m}^{-3}\right)$ while no differences were detected between Baseline and Anomaly_2 scenarios. In general, the influence of transplanting time on this parameter could be considered no significant.

\section{Conclusions}

This study has provided details relating to the responses of crops under climate change and also, how the sowing or transplanting optimization may be used to maximize the crop yield.

Ventrella et al. (2011), utilizing the same climate data-set and crop models of this study, verified that climate change could negatively affect yields of winter durum wheat and especially those of tomato with the differences in crop responses between the two crops depending on the interaction between crop phenology and climate conditions and with the phenological cycle of spring crops occurring in a period of the year (from April to August) that will be characterized by higher changes in minimum and maximum temperatures compared to Baseline scenario. Moreover, they highlighted that limiting the global mean temperature change of $2^{\circ} \mathrm{C}$, the application of adaptation strategies, as irrigation and nitrogen fertilization, showed a positive effect in minimizing the negative impacts of climate change on productivity of tomato cultivated in southern Italy. For a temperature change of around $5^{\circ} \mathrm{C}$, environmental conditions are likely to exceed the adaptation capacity of the investigated crop cultivars and, at least for tomato cultivation in southern Italy, it would not be possible to restore the yield level of the Baseline.

The results of this study complements these conclusions with the following indications related to another adaptation strategy that is the choice of the sowing/transplanting time. In the forecasted scenario of southern Italy, delayed sowings (until end of November) allowed to maximize the yield of winter durum wheat. For a global temperature change of $5^{\circ} \mathrm{C}$, with such delayed sowings it was possible to obtain the same yield level of the Baseline. Without adaptation, the climate change forecasted for Southern Italy was predicted to induce a yield reduction of tomato of 7 and $21 \%$ with the global temperature increase by 2 and $5^{\circ} \mathrm{C}$, respectively. Moreover, under global temperature increase by $5^{\circ} \mathrm{C}$, early transplanting times could minimize the negative impact of climate change on crop productivity but the intensity of this effect was not sufficient to restore production levels of the Baseline. However, these conclusions do not take into account the possible and wished-for genetic progress that could expand the adaptation capacity
Finally, despite the uncertainties of climatic and crop models, the simulation results of our study showed the ability of CROPGRO and CERES-Wheat models to provide useful tools to evaluate cropping management options under climate change.

\section{References}

Alexandrov VA, Hoogenboom G, 2000. The impact of climate variability and change on crop yield in Bulgaria. Agr. Forest Meteorol. 104:315-327.

Arora VK, Singh H, Singh B, 2007. Analyzing wheat productivity responses to climatic, irrigation and fertilizer-nitrogen regimes in a semi-arid sub-tropical environment using the CERES-Wheat model. Agr.l Water Manage. 94:22-30.

Boote KJ, Jones JW, Hoogenboom G, Pickering NB, 1998. The CROPGRO model for grain legumes. pp 99-128 in: G.Y. Tsuji, G. Hoogenoboom and P. Thornton (eds.) Understanding options for agricultural production. Kluwer Academic Publ., Dordrecht, the Netherlands.

Brassard JP, Singh B, 2008. Impacts of climate change and C02 increase on agriculture production and adaptation options for southern Québec, Canada. Mitig. Adapt. Strat. Global Change 13:241-265.

Cabrera VE, Jagtap SS, Hildebrand PE, 2007. Strategies to limit (minimize) nitrogen leaching on dairy farms driven by seasonal climate forecasts. Agr. Ecosyst. Environ. 122:479-489.

Cuculeanu V, Marica A, Simota C, 1999. Climate change impact on agricultural crops and adaptation options in Romania. Climate Res. 12:153-160.

European Environment Agency, 2007. Climate change and water adaptation issues. EEA Technical report No 2/2007. EEA Publ., Copenhagen, Denmark.

Gibelin AL, Déqué M, 2003. Anthropogenic climate change over the Mediterranean region simulated by a global variable resolution model. Clim. Dyn. 20:237-339.

Giglio L, Charfeddine M, Lopez R, Sollitto D, Ventrella D, Ruggieri S, Rinaldi M, Castrignanò A, 2010. Analisi spazio-temporale degli effetti dei cambiamenti climatici su frumento e pomodoro in capitanata. pp 13-14 in Atti $13^{\circ}$ Conv. Naz. Agrometeorologia, Bari, Italy.

Giorgi F, Lionello P, 2008. Climate change projections for the Mediterranean region Global Planet. Change 63:90-104.

Hoogenboom G, Jones JW, Wilkens PW, Batchelor WD, Bowen WT, Hunt LA, Pickering NB, Singh U, Godwin DC, Baer B, Boote KJ, Ritchie JT, White JW 1994. Crop models. In: G.Y. Tsuji, G. Uehara and S. Balas (eds.) DSSAT Ver. 3, Vol. 2. University of Hawaii Publ., Honolulu, HI, USA, pp 95-244.

Hoogenboom G, 2000. Contribution of agrometeorology to the simulation of crop production and its application. Agr. Forest Meteorol. 103:137-157.

Hatfield J, 2008. Agriculture. In: P. Backlund, A. Janetos and D. Schimel (eds.) The effects of climate change on agriculture, land resources, water resources, and biodiversity in the United States. Synthesis and Assessment Product 4.3. Climate Change Science Program, Washington, DC, USA, pp 21-74.

Intergovernmental Panel on Climate Change, 2007. Climate Change 2007: The Physical Science Basis. Contribution of Working Group I to the Fourth Assessment Report of the Intergovernmental Panel on Climate Change. Cambridge University Press, Cambridge, UK.

Iqbal MA, Eitzinger J, Formayer H, Hassan A, Heng LK, 2011. A simulation study for assessing yield optimization and potential for water 
reduction for summer-sown maize under different climate change scenarios. J. Agr. Sci. 149:129-143.

Jones JW, Hoogenboom G, Porter CH, Boote KJ, Batchelor WD, Hunt LA, Wilkens PW, Singh U, Gijsman AJ, Ritchie JT, 2003. The DSSAT cropping system model. Eur. J. Agron. 18:235-265.

Lal M, Singh KK, Rathore LS, Srinivasan G, Saseendran SA, 1998. Vulnerability of rice and wheat yields in Northwest India to future changes in climate. Agr. Forest Meteorol. 89:101-114.

Luo Q, Bellotti W, Williams M, Wang E, 2009. Adaptation to climate change of wheat growing in South Australia: Analysis of management and breeding strategies. Agri. Ecosyst. Environ. 129:261-267.

Magrin G0, Travasso MI, Díaz RA, Rodríguez R0, 1997. Vulnerability of the agricultural systems of Argentina to climate change. Clim. Res. 9:31-36.

Mizina SV, Smith JB, Gossen E, Spiecker KF, Witkowsk SL, 1999. An evaluation of adaptation options for climate change impacts on agriculture in Kazakhstan. Mitig. Adapt. Strat. Global Change 4:2541.

Olesen JE, Carter TR, Díaz-Ambrona CH, Fronzek S, Heidmann T, Hickler T, 2007. Uncertainties in projected impacts of climate change on European agriculture and terrestrial ecosystems based on scenarios from regional climate models. Climatic Change $81: 123-143$

Parry ML, Rosenzweig C, Iglesias A, Livermore M, Fischer G, 2004. Effects of climate change on global food production under SRES emissions and socio-economic scenarios. Global Environ. Change 14:53-67.

Rinaldi M, 2001. Durum wheat simulation in southern Italy using CERES-Wheat model. I. Calibration and validation. pp 81-82 in Proc. 2nd Int. Symp. on Modelling Cropping Systems, Florence, Italy.

Rinaldi M, Ubaldo R, 2007. Simulation at regional level of irrigated wheat and tomato in a Mediterranean environment. Water Res. Manage. 4:569-581.

Rinaldi M, Ventrella D, Gagliano C, 2007. Comparison of nitrose and irrigation strategies in tomato using CROPGR0 model. A case study from Southern Italy. Agr. Water Manage. 87:91-105.

Ritchie JT, Singh U, Godwin DC, Bowen WT, 1998. Cereal growth, development and yield. In: G.Y. Tsuji, G. Hoogenboom and P.K. Thornton (eds.) Understanding options for agricultural production. Kluwer Academic Publ., Dordrecht, The Netherlands, pp 79-98.

Rosenzwieg C, Parry ML, 1994. Potential impact of climate change on world food supply. Nature 367:133-138.

Rosenzweig C, Tubiello FN, 1996. Effects of changes in minimum and maximum temperature on wheat yields in the central US: a simulation study. Agr. Forest Meteorol. 80:215-230.

Salinger MJ, Sivakumar MVK, Motha R, 2005. Reducing vulnerability of agriculture and forestry to climate variability and change: Workshop summary and recommendations. Climatic Change 70:341-362

Scholberg JMS, Boote KJ, Jones JW, McNeal BL, 1997. Adaptation of the CROPGRO model to simulate the growth of field-grown tomato. In: M.J. Kropff, P.S. Teng, P.K. Aggarwal, J. Bouma, B.A.M. Bouman, J.W. Jones and H.H. van Laar (eds.) Systems approaches for sustainable agricultural development: applications of systems approaches at the field level. Kluwer Academic Publ., Dordrecht, The Netherlands, pp 133-151.

Semenov MA, Barrow EM, 1997. Use of a stochastic weather generator in the development of climate change scenarios. Climatic Change 35:397-414

Semenov M.A. 2007. Development of high resolution UKCIP02-based climate change scenarios in the UK. Agricultural and Forest Meteorology 144:127-138.
Smit B, Skinner MW, 2002. Adaptation options in agriculture to climate change: A typology. Mitig. Adapt. Strat. Global Change 7:85-114.

Stigter CJ, Dawei Z, Onyewotu LOZ, Xurong M, 2005. Using traditional methods and indigenous technologies for coping with climate variability. Climatic Change 70:255-271.

Stöckle CO, Donatelli M, Nelson R, 2003. CropSyst, a cropping systems simulation model. Eur. J. Agron. 18:289-307.

Stuczyinski T, Demidowicz G, Deputat T, Górski T, Krazowicz S, Kus J, 2000. Adaptation scenarios of agriculture in Poland to future climate changes. Environ. Monit. Assess. 61:133-144.

Thorp KR, DeJonge KC, Kaleita AL, Batchelor WD, Paz J0, 2008. Methodology for the use of DSSAT models for precision agriculture decision support. Computer. Electron. Agr. 64:276-285.

Timsina J, Godwin D, Humphreys E, Singh Y, Singh B, Kukal SS, Smith D, 2008. Evaluation of options for increasing yield and water productivity of wheat in Punjab, India using the DSSAT-CSM-CERESWheat model. Agr. Water Manage. 95:1099-1110.

Trnka M, Dubrovsky M, Semerádová D, Žalud Z, 2004. Projections of uncertainties in climate change scenarios into expected winter wheat yields. Theor. Appl. Climatol. 77:229-249.

Tsuji GY, Hoogenboom G, Thornton PK, 1998. Understanding options for agricultural production. Systems approaches for sustainable agricultural development. Kluwer Academic Publ., Dordrecht, The Netherlands.

Tubiello FN, Donatelli M, Rosenzweig C, Stöckle CO, 2000. Effects of climate change and elevated CO2 on cropping systems: model predictions at two Italian locations. Eur. J. Agron. 13:179-189.

Tubiello FN, Ewert F, 2002. Simulating the effects of elevated CO2 on crops: approaches and applications for climate change. Eur. J. Agron. 18:57-74.

Tubiello FN, Rosenzweig C, Goldberg RA, Jagtap S, Jones JW, 2002. Effects of climate change on US crop production: simulation results using two different GCM scenarios. Part I: Wheat, potato, maize, and citrus. Clim. Res. 20:259-270.

Tubiello FN, Rosenzweig C, Volk T, 1995. Interactions of CO2, temperature, and management practices: simulations with a modified version of CERES-Wheat. Agr. Syst. 49:135-152.

Van Viet N, 2001. The influence of climatic variation on the production of winter-spring rice in the north delta of Vietnam and the means to cope with it. CAgM Report No. 77b, WMO/TD No. 1029, World Meteorological Organization Publ., Geneva, Switzerland.

Ventrella D, Giglio L, Rinaldi M, Lopez R, Moriondo M, 2009a. Vulnerabilità e adattamento agronomico ai cambiamenti climatici sui bilanci idrici di alcune coltivazioni nell'Italia Meridionale. Riv. Ital. Agrometeorol. 2:18-19.

Ventrella D, Rinaldi M, Charfeddine M, Ruggieri S, Giglio L, Moriondo M, 2009b. Adattamento ai cambiamenti climatici per frumento duro e pomodoro in ambiente Mediterraneo: irrigazione e concimazione azotata. pp 67-68 in Atti XXXVIII Conv. Naz. Società Italiana di Agronomia, Firenze, Italy.

Ventrella D, Charfeddine M, Moriondo M, Rinaldi M, Bindi M, 2011. Agronomic adaptation strategies under climate change for winter durum wheat and tomato in southern Italy: irrigation and nitrogen fertilization. Reg. Environ. Change. DOI 10.1007/s10113-011-02563.

Wall E, Smit B, 2005. Climate change adaptation in light of sustainable agriculture. J. Sustain. Agr. 27:113-123.

Wheaton EE, Mclver DC, 1999. A framework and key questions for adapting to climate variability and change. Mitig. Adapt. Strat. Global Change 4:215-225.

Williams JR, Jones CA, Kiniry JR, Spanel DA, 1989. The EPIC crop growth model. T. ASAE 32:497-511. 